\title{
Diversity of Lactobacilli in the Oral Cavities of Young Women with Dental Caries
}

\author{
P.W. Caufield Y. Li A. Dasanayake D. Saxena \\ College of Dentistry, New York University, New York, N.Y., USA
}

\author{
Key Words \\ Dental caries $\cdot$ Lactobacillus $\cdot$ Phylogeny, bacterial \\ diversity $\cdot 16 \mathrm{~S}$ rDNA
}

\begin{abstract}
For nearly a century, lactobacilli (LB) in the oral cavity have been generally associated with dental caries. Here, we characterized the LB isolated from the saliva of 6 women with active caries using genetic-based taxonomical identification methods. From each subject, 30 isolates growing on Rogosa medium and presumed to be LB were analyzed. Of the 180 isolates, 176 were further characterized by biotyping, DNA melting points, DNA chromosomal fingerprinting, genotyping, and phylogenetic cluster assessment. We found a total of 30 unique genotypes of LB in the saliva of caries-active women, with each woman harboring between 2 and 8 distinct genotypes. Although Lactobacillus vaginalis, L. fermentum, and L. salivarius were found in 4 of 6 of the subjects, results from other studies using comparable methods show an entirely different array of LB associated with caries. These collective observations lead us to surmise that $L B$ associated with dental caries are likely exogenous and opportunistic colonizers, arising from food or other reservoirs outside the oral cavity.

Copyright $\odot 2007$ S. Karger AG, Basel
\end{abstract}

The lactobacilli (LB) comprise a diverse group of more than 80 species [Satokari et al., 2003] and are widely dispersed in nature, with ecological habitats that include plants, certain foods that require lactic acid fermentation (mostly dairy products) and animals [Hammes and Vogel, 1995]. This wide distribution in nature underpins the remarkable variety and genetic composition of the genus, with $\% \mathrm{G}+\mathrm{C}$ contents ranging from 30 to $53 \%$ [London, 1976].

LB isolated from the human gastrointestinal tract or vagina are considered by many to be members of the human indigenous biota, conferring beneficial effects for the host by excluding the colonization of exogenous pathogens as well as some elaborating $\mathrm{H}_{2} \mathrm{O}_{2}$ and other antimicrobial factors [Hillier et al., 1993; Tannock, 2004]. In contrast, LB found in the human oral cavity have been correlated to presence and progression of dental caries for almost a century [Kligler and Gies, 1915].

For decades, and for compelling reasons, LB were considered as the major etiological agent of dental caries. LB are prolific lactic acid producers (acidogenic) as well as acid-tolerant (aciduric) [Cotter and Hill, 2003; Marsh and Martin, 1999]. They are routinely and consistently isolated from caries-active sites [Byun et al., 2004; Chhour et al., 2005; Marchant et al., 2001; Munson et al., 2004] and in most caries studies, and even in some private dental offices, an assay for LB counts is included. Because of their association with caries after the lesion is formed, LB are considered secondary invaders, rather than initiators,

\section{KARGER}

Fax +41613061234

E-Mail karger@karger.ch

www.karger.com
(C) 2007 S. Karger AG, Basel

Accessible online at: www.karger.com/cre
P.W. Caufield, DDS, PhD

New York University, College of Dentistry

345 E. 24th Street, Room 1024, Kriser Building

New York, NY 10010 (USA)

Tel. +1 212998 9603, Fax +1 212995 3994, E-Mail pwc2@nyu.edu 
in the caries process [Marsh and Martin, 1999; Tanzer et al., 2001; van Houte, 1980]. In adults, LB predominate in advanced lesions, vastly outnumbering even Streptococcus mutans [Byun et al., 2004; Chhour et al., 2005]. In young children with severe early childhood caries, however, LB are found, but not as the predominant genus as with adult lesions [Becker et al., 2002]. Their habitat in the oral cavity includes retentive niches such as pits and fissures and caries lesions [Loesche et al., 1984; Tanzer et al., 2001; van Houte, 1980]. Two observations, however, suggest that LB found in the oral cavity may not be members of the normal indigenous biota of humans: (1) LB are rarely found in the oral cavity of infants, even after teeth emerge [Carlsson and Gothefors, 1975; Carlsson et al., 1975], and (2) in young adults with dental caries and lactobacilli infection, the levels of LB often drop to undetectable levels following caries removal and placement of restorations [Wicht et al., 2004; Wright et al., 1992].

The vast majority of caries studies report total counts of LB present on selective media (e.g., Rogosa medium). The first question that continues to elude caries researchers is whether there is a specific species or phylogenetically distinct group of LB associated with dental caries in humans. This question becomes important because another group of cariogenic organism consistently isolated from caries lesions, the mutans streptococci, are indigenous to humans, as are many commensal microorganisms in the gastrointestinal tract and other host systems in which the host and parasite undergo coevolution [Hooper and Gordon, 2001]. The second question, therefore, is whether or not the LB associated with dental caries are members of the human (specifically oral) indigenous biota.

Efforts to precisely identify LB to the species level have been difficult due to the lack of reliable and precise taxonomical identifiers. This difficulty is further intensified using biochemical reactions for species identification, up to 17 phenotypic tests sometimes being required for speciation [Hammes and Vogel, 1995]. Because of the difficulties associated with accurate characterization, most clinical studies report simply counts of 'lactobacilli' on selective media. With the advent of molecular and genetic typing methods, however, including species-specific primers and distinctive 16S rDNA segments [Byun et al., 2004; Chhour et al., 2005], the task of identifying the LB has become more achievable. This is important because if the specificity exists between a few species of Lactobacillus and caries, those species could be further characterized and their natural history better understood so as to gain insight into their natural reservoirs, perhaps devising methods to prevent their transmission and acquisition.
This study was conducted to characterize the LB population in the oral cavity of young female adults with existing caries lesions to determine the diversity of LB and whether a single species or genotype prevails among individuals of similar racial/ethnic backgrounds, with similar caries histories, and/or from similar geographical populations.

\section{Materials and Methods}

\section{Study Population}

The study population was derived from a larger cohort of firsttime mothers ( $\mathrm{n}=50$; ages $16-28$ years) of African-American descent living in Birmingham, Ala. [for more details, see Li et al., 2005]. The study protocol and informed consent were approved by the Institutional Review Board of the University of Alabama Birmingham. Six healthy women in this study were selected from the above cohort based upon having LB present in their saliva and exhibiting consistently high levels (an average of $3.4 \times 10^{5} \pm 3.0$ $\times 10^{5}$ ) of $\mathrm{LB}$ on at least two separate samples taken at the baseline oral examination of the study. The mean age of the women was 21.5 years and the mean caries scores measured by the DMFT and DMFS (decay, missing, and filled tooth and tooth surface) were 7.7 (range 5-11) and 16.1 (range 12-24), respectively.

\section{Bacterial Sample Collections}

Stimulated whole saliva was obtained from each subject. They were asked to chew paraffin wax and not swallow for $30 \mathrm{~s}$, and then gently expectorated $1-2 \mathrm{ml}$ of saliva directly into a centrifuge tube. Two hundred microliters of saliva was then added to $1.8 \mathrm{ml}$ of reduced transport medium [Syed and Loesche, 1973]; the samples were placed on ice and processed within $3 \mathrm{~h}$ as previously described [Caufield et al., 1993; Li et al., 2005]. Samples were autoplated (Spiral Autoplate ${ }^{\circledR}$ 4000; Spiral Biotech, Inc., Bethesda, Md., USA) onto Rogosa SL (Difco Laboratories, Detroit, Mich., USA) for the selective cultivation of Lactobacillus sp. [Rogosa et al., 1951]. After 3 days incubation at $37^{\circ} \mathrm{C}$ in an anaerobic environment, total colony-forming units were estimated per the manufacturer's standardized method (Spiral Biotech, Inc., Bethesda, Md., USA). A total of 180 isolates, 30 per subject, with distinct colonies were picked at random from the Rogosa plates for all 6 subjects. Efforts were made to include each of the different colony morphologies. Each isolate was Gram-stained, pure streaked onto the Rogosa medium and a single, well-isolated colony was picked, pure-cultured again, and then colonies collected and stored frozen at $-70^{\circ} \mathrm{C}$ in MRS broth (Difco) with $15 \%$ glycerin for further characterization. Of the 180 isolates from 6 individuals, 4 were excluded because Gram stain and cell morphology were inconsistent with Lactobacillus. The remaining 176 isolates were subject to biochemical and genetic profiling.

\section{Phenotypic Determinations}

Each of the isolates was regrown from frozen stock and subjected to biochemical characterization using the API $50 \mathrm{CHL}$ (bioMérieux, Hazelwood, Mo., USA). Type strains including $L$. casei ATCC393, L. acidophilus ATCC4356, L. casei ATCC4646, L. rhamnosus ATCC7469, L. casei subsp. ATCC11578, L. salivarius 
subsp. salivarius ATCC11741, L. salivarius subsp. salicinius ATC11742, L. fermentum ATCC14931, L. paracasei subsp. paracasei ATCC25598, and L. paracasei subsp. tolerans ATCC25599 were obtained from the American Type Culture Collection (ATCC; Manassas, Va., USA) - all serving as controls for the various tests. Bacterial cell densities were adjusted according to the manufacturer's instructions. Readings were taken after both 24 and $48 \mathrm{~h}$ aerobic incubation at $37^{\circ} \mathrm{C}$. Species level assignments were made using the API CH Lab software package. Additionally, the BBL Minitek biochemical differentiation system (BBL Microbiology System, Cockeysville, Md., USA), including arginine and esculin hydrolysis and fermentation with raffinose, melibiose, sorbitol, and mannitol were performed for all isolates to supplement or validate the API 50 assignments.

\section{DNA Isolation}

Whole chromosomal DNA was isolated from each isolate after overnight growth on MRS media (Difco) under conditions described above. Cell lysis and DNA extraction was accomplished as described for S. mutans [Li and Caufield, 1995] except that MRS medium was used for growing cells. DNA was isolated with the use of the QIAGEN Genomic-tip 100 (QIAGEN Inc., Valencia, Calif., USA) according to manufacturer's instructions.

\section{Chromosomal DNA Fingerprinting}

Genotypes of Lactobacillus sp. were determined by chromosomal DNA fingerprinting using the method described for $S$. $m u$ tans [Caufield and Walker, 1989; Li and Caufield, 1995]. DNA was digested with various restriction enzymes to determine which would produce the optimal fingerprint. The enzymes used were HaeIII, BamHI, ClaI, EcoRI, EcoRV, HindIII, HincII, PstI, SalI, SmaI, XbaI and XhoI. Digests were run overnight on $0.55 \%$ agarose gels and profiles were captured as described previously [Li and Caufield, 1995].

\section{$\% G+C$ Content Determination}

Whole chromosomal DNA prepared above was adjusted to a concentration of $20 \mu \mathrm{g} / \mathrm{ml}$ in $0.1 \times$ SSC buffer. Salmon sperm DNA at the same concentration was used as a positive control. DNA melting points $\left(\mathrm{T}_{\mathrm{m}}\right)$ were determined by using a spectrophotometer and temperature controller (DU 7400 UV/Vis, Peltier, Beckman, Fullerton, Calif., USA) with a temperature ramp of $1{ }^{\circ} \mathrm{C} / \mathrm{min}$ over a range of $25-90^{\circ} \mathrm{C}$. The $\% \mathrm{G}+\mathrm{C}$ was calculated using the formula $\% \mathrm{G}+\mathrm{C}=\left(\mathrm{T}_{\mathrm{m}}-53.9\right) \times 2.4$ [Marmur and Doty, $1962]$ and the Beckman software program.

\section{$16 S$ rDNA Amplification and Analysis}

The primers, LactoF (5'-TGGAAACAGRTGCTAATACCG$\left.3^{\prime}\right)$ and LactoR (5'-GTCCATTGTGGAAGATTCCC-3') [Byun et al., 2004], were used to amplify an approximately 232-bp region of the V2-V3 region of the16S rDNA locus of Lactobacillus spp. PCRs were performed in a reaction volume of $50 \mu \mathrm{l}$, containing PCR buffer (20 mM Tris- $\mathrm{HCl}, \mathrm{pH} 8.4 ; 50 \mathrm{mM} \mathrm{KCl}), 1.5 \mathrm{mM} \mathrm{MgCl}_{2}$, $0.5 \mathrm{mM}$ dNTPs (Invitrogen, Carlsbad, Calif., USA), $0.5 \mu \mathrm{M}$ of each primer, 1 unit of Taq DNA Polymerase (Invitrogen), and $1.0 \mu \mathrm{l}$ of genomic DNA prepared as described above. PCR amplification was performed in a Gene Amp thermal cycler (Applied Biosystems, Foster City, Calif., USA) under the following conditions: an initial cycle of $95^{\circ} \mathrm{C}$ for $15 \mathrm{~min}$, then 40 cycles of $95^{\circ} \mathrm{C}$ for $15 \mathrm{~s}$, $62^{\circ} \mathrm{C}$ for $1 \mathrm{~min}$. The PCR products were analyzed by electropho- resis in a $1 \%$ agarose gel. Fragments of approximately 230 bp resulting from the PCR were purified and sequenced in both directions using the LactoF and LactoR primers.

Sequences obtained were then compared to $16 \mathrm{~S}$ rDNA gene sequences in the Ribosomal Database Project II [Cole et al., 2005]. Taxonomic identity to the species level was assigned based on the highest similarity score. Sequences representing the unique genotypes from the 6 subjects were aligned with CLUSTAL W [Thompson et al., 1994] and distance trees were produced with the PAUP* program [Swofford, 1998] using a neighbor-joining approach [Saitou and Nei, 1987]. Statistical support for tree clusters was assessed via bootstrap analysis (1,000 reps). Sequence from $S$. $m u$ tans UA159 (accessional number NC004350) was used as the outgroup to root the tree.

\section{Results}

From 6 women with active caries and who consistently harbored LB in the saliva, 180 isolates $(6$ subjects $\times 30$ isolates) presumed to be LB were picked from Rogosa medium. One hundred and seventy-six of the isolates were confirmed as belonging to the genus Lactobacillus using the API 50 CHL biotyping system.

As shown in figure 1, restriction digest of chromosomal DNA with HindIII obtained from a representative group of isolates yielded clear and distinguishable fingerprints capable of separating isolates of LB. Among the different restriction enzymes tested, both HindIII and $P v u \mathrm{I}$ (data not shown) yielded distinct and well-resolved patterns. From the 176 isolates of $\mathrm{LB}, \mathrm{CDF}$ revealed 30 distinct genotypes with an average of 5 genotypes per subject (range 2-11). Interestingly, no common CDF patterns were observed between the subjects. One subject (S87) harbored 11 genotypes.

Determining the biochemical profiles and $\% \mathrm{G}+\mathrm{C}$ content $\left(\mathrm{T}_{\mathrm{m}}\right)$ of individual strains proved tedious and less precise than molecular genetic data to assign strains to taxa (fig. 2). In some instances, the $\mathrm{T}_{\mathrm{m}}$ of genomic DNA within a cluster varied nearly $10 \%$ (L. vaginalis cluster; fig. 2).

The results of $16 \mathrm{~S}$ rDNA profiling yielded 9 different taxonomical clusters as displayed on the phylogram (fig. 2$)$, with an overall mean $( \pm S D)$ similarity score $\geq 0.986 \pm 0.02$ to known strains of Lactobacillus present in the RDPII database. Of the nine taxa found in 6 subjects, L. vaginalis, L. fermentum, and L. salivarius were isolated from 4 subjects. Although the same species was common to more than one individual, no two strains from different individuals exhibited the same genotype (chromosomal DNA profile). Bootstrap values supported well the assignment of taxa to the various clusters along 
Fig. 1. Chromosomal DNA fingerprinting of representative subsample of Lactobacillus spp. obtained from 6 young adult women. Chromosomal DNA was digested with HindIII and the resulting fragments electrophoresed in agarose gels, stained with ethidium bromide and photographed under UV light. The far left lane displays the size standard with size (in $\mathrm{kb}$ ) in the margin.

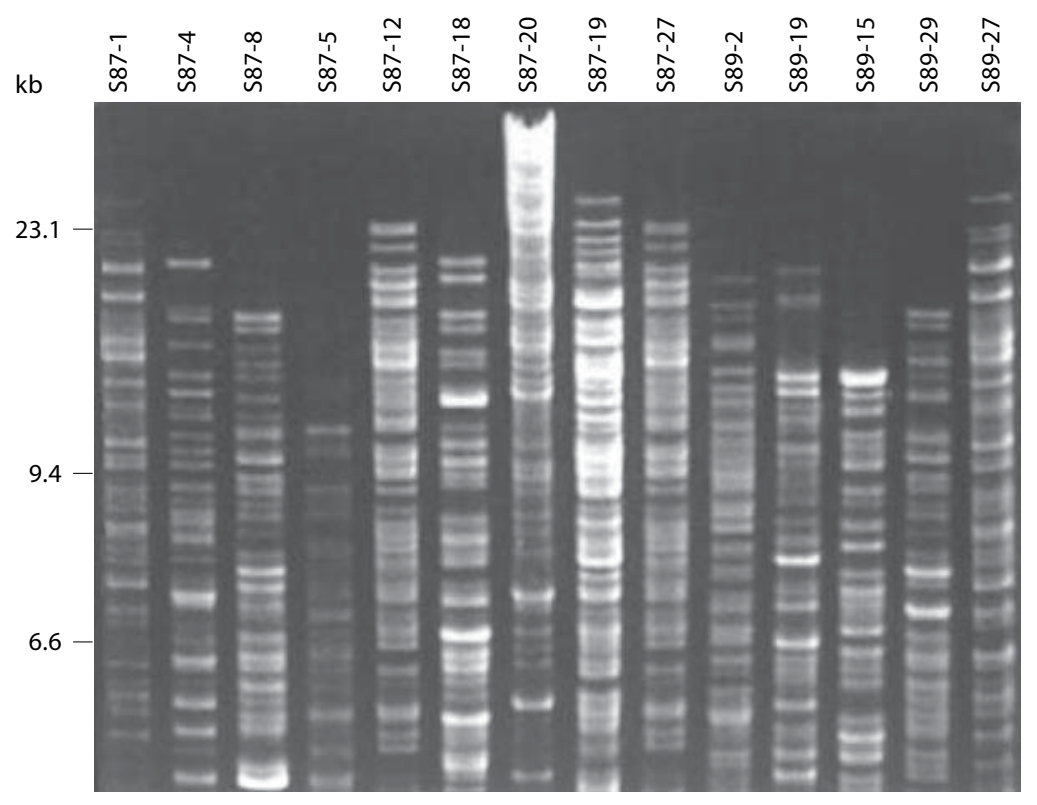

with their best match from the RDPII. Not surprisingly, the clade (L. vaginalis) with the least support, i.e., lowest bootstrap value of $65 \%$, also exhibited the most disparate range of $\% \mathrm{G}+\mathrm{C}$ values ( $\sim 10 \%$; fig. 2 ).

\section{Discussion}

We do not know whether all or most of the Lactobacillus found in the stimulated saliva are derived solely from the retentive tooth sites and caries lesions. Most culturebased diagnostic tests are designed to detect bacteria in saliva, likely because of convenience as well as because saliva reflects the overall bacterial levels in the oral cavity [Keene, 1986]. Presumably, the chewing on paraffin wax wafers liberates bacteria from the tooth surfaces into the saliva. Other potential reservoirs, besides the retentive areas of the dentition, could include the mucosal surfaces of the mouth and the tongue. Studies by Wright et al. [1992] showed that LB present in saliva decreased to low or undetectable levels following comprehensive dental restorations. This observation suggests that LB in saliva are primarily derived from caries lesions and other retentive areas such as fissures. Indirectly, the fact that young children do not generally harbor LB [Carlsson et al., 1975], confirmed by a study by our group [Lu et al., 1999], argues in favor of caries lesions and other retentive sites of the dentition as the major site for the retention of LB in the oral cavity.

The culture medium most commonly used to cultivate oral samples, Rogosa agar, works well in limiting growth almost exclusively to LB. As shown in the present study, $176 / 180(98 \%)$ of the colonies picked and characterized from Rogosa medium belong to the genus Lactobacillus based on cell morphology and Gram stain, biochemical attributes and DNA sequence analysis. Past efforts to characterize LB to the species level required a fairly extensive battery of tests [Hammes and Vogel, 1995] to make even an approximate estimation of species affiliation.

Several studies [Byun et al., 2004; Chhour et al., 2005; Munson et al., 2004], coupled with the present data, make a compelling argument for using direct sequencing of the $16 \mathrm{~S}$ rDNA locus to identify Lactobacillus to the species level. With the recent compilation of $16 \mathrm{~S}$ rDNA sequences with biochemical and morphological features of designed type strains plus sequences from nontype strains, the Ribosomal Database II now allows more precision in taxonomical identification based on $16 \mathrm{~S}$ rDNA sequences [Cole et al., 2005]. Along with others [Byun et al., 2004; Chhour et al., 2005], we assigned strains of LB to taxa and constructed a phylogenetic tree based on only a portion of the $16 \mathrm{~S}$ rDNA sequence. It could be argued that this amount of sequence ( $\sim 230 \mathrm{bp})$ may be insufficient for species level assignment of some bacterial groups [Hugenholtz et al., 


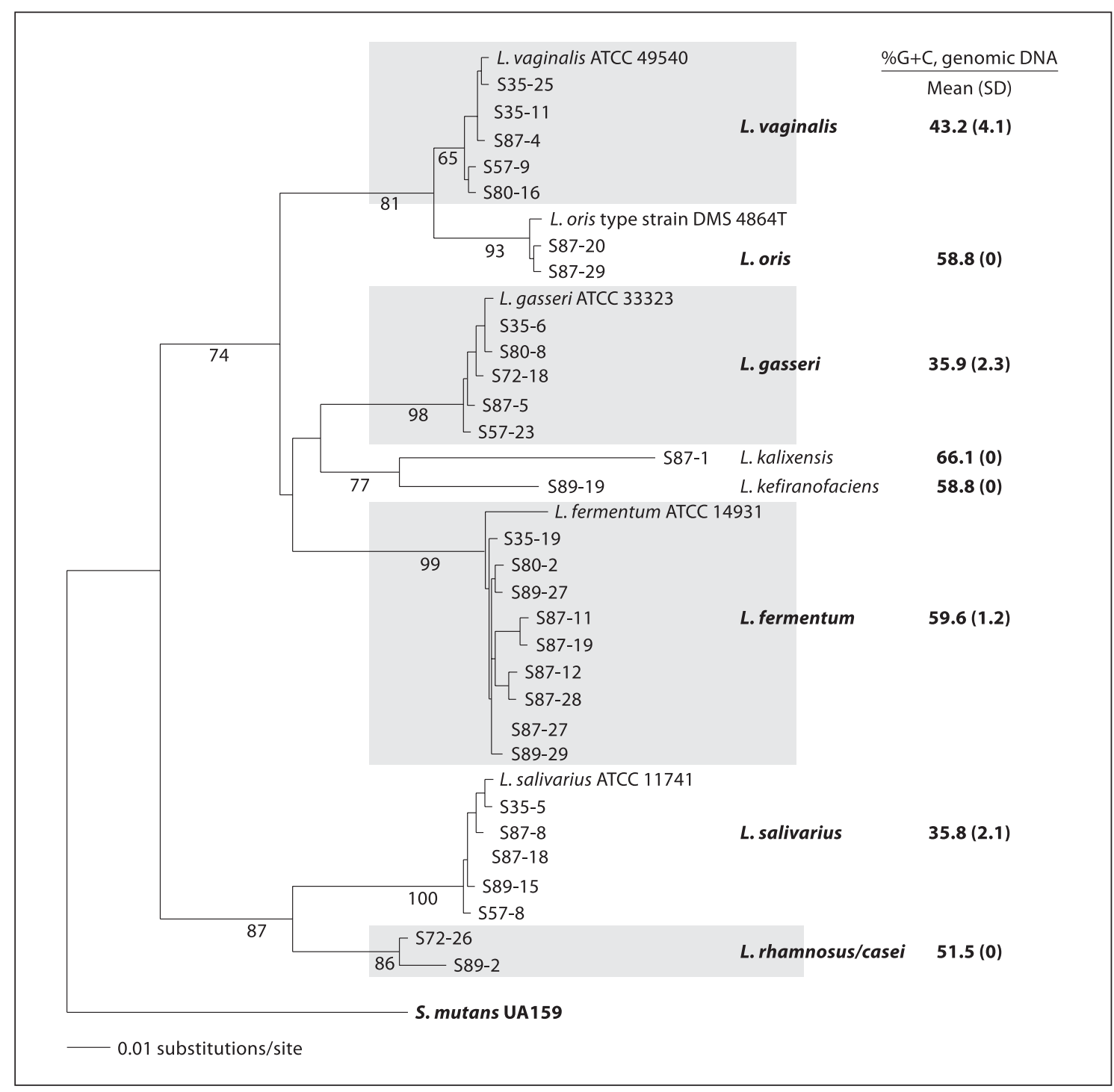

Fig. 2. Phylogenetic analysis of the V2-V3 region of $16 \mathrm{~S}$ rDNA amplicons from 30 Lactobacillus clinical strains along with known sequences designated as a Bergey's type strain from the Ribosomal Database II with the closest match to each cluster of clinical samples. Fragments were first aligned using ClustalW along with known reference strains. Type strain S. mutans UA159 served as the designated out-group and the Lactobacillus sequences con-

1998]; the support for each major taxonomical cluster as determined from bootstrap analysis, including a documented strain from the ATCC or DMS within the phylogenetic tree (fig. 2), appears reasonably robust. Using a cutoff point for a $\leq 1 \%$ similarity of sequences for species assignment [Chhour et al., 2005] for the genus Lactobacillus may be too stringent given the widely disparate diversity as is evident by the range of $\% \mathrm{G}+\mathrm{C}$ content within the ge- strained to be monophyletic to the out-group after a tree was constructed using the Neighbor-Joining algorithm. Bootstrap values from 1,000 replicates are shown at each node. Seven well-supported clades containing 9 taxonomical entities were evident. Along the right side of each clade is the average $\% \mathrm{G}+\mathrm{C}$ content (and SD) of whole genomic DNA from each of the 30 strains of LB.

nus. In the present study, however, the average similarity score with sequences archived in the RDBII was 0.984 with $57 \%$ of the strains falling within the $1 \%$ cutoff point.

In the present study, we found 9 different species or phylotypes of Lactobacillus present in 6 young adults with caries. We did not anticipate finding so much diversity among subjects of similar racial, socioeconomical and geographical backgrounds. In a more extensive sur- 
vey of caries lesions in extracted teeth from adult population, however, Byun et al. [2004] report at least 18 phylotypes of Lactobacillus. The authors were unable to demonstrate a consistent or common specific species or genotypes of Lactobacillus uniquely associated with dental caries, leading them to speculate that 'environmental influences, particularly dietary influences, have a determining role in colonization profiles within lesions'. In a corollary study which examined a subset of advanced caries in extracted teeth of adults [Chhour et al., 2005], DNA amplicons consistent with LB were found to comprise $50 \%$ of the sample, although the authors observed a wide range of both total counts and diversity within the samples. Over 14 distinct taxa of Lactobacillus were identified, with 9 phylotypes more frequently found, supporting the notion that no single group or phylotype of LB characterizes caries lesions. Studies by Munson et al. [2004] also reported up to 14 different species of Lactobacillus. In children, Becker et al. [2002] reported finding LB only in low levels and only in deeper lesions among children with severe childhood caries. Using a PCRbased typing system, Marchant et al. [2001] found L. casei, L. fermentum, and L. rhamnosus to be the predominant LB in advanced caries lesions. The present study in conjunction with those cited above collectively underscore the extreme degree of diversity of LB between individuals and even between lesions within the same individual. The widely divergent species or genotypes found within the oral cavity of individuals with caries suggests that the natural reservoir of LB resides outside humans.

In the present study, for further characterization, we used a modification of a chromosomal DNA fingerprinting technique developed for genotyping S. mutans for genotyping LB, similar to a chromosomal DNA fingerprinting method proposed by other investigators [Zhong et al., 1998]. By first genotyping isolates, the pool of potential strains to sequence decreased from 176 to 30 . While CDF requires a fair amount of effort to execute, other typing methods based on DNA, such as probes using intergenic spacer region [Walter et al., 2001], ribotyping [Zhong et al., 1998], and rep-PCR DNA fingerprinting [Antonio and Hillier, 2003; Marchant et al., 2001] also require considerable effort. One interesting result of genotyping all 176 isolates of LB was the finding that no single genotype was common to any 2 individuals, i.e. each subject harbored a unique set of LB genotypes. This observation does not support the concept that LB arise from a common food source even though most of the observations from the present study and from other studies strongly suggest that the source of LB in the human oral cavity is external, possibly from fermented foods. Other investigators failed to show a common Lactobacillus between vaginal samples and food sources [Pavlova et al., 2002], but there are likely as many strains of LB in food as there are found in humans, and thus not finding a common food source is not surprising.

If a specific species or group of Lactobacillus cannot be consistently found associated with dental caries in geographically and age-specific populations of humans, then the question arises - are LB members of the human indigenous biota? None of the recent studies using $16 \mathrm{~S}$ rDNA sequences, including the present study, were able to narrow the list of potential candidates to a few species [Byun et al., 2004; Chhour et al., 2005]. Because LB are so widely distributed in nature, it seems reasonable to speculate that the natural reservoir for this group lies outside human hosts, perhaps in food. Dental caries is for the most part a disease of modern humans, correlated to the agriculturally intensive cultivation and consequent consumption of refined sugar. Presucrose ancestors and extant humans living in remote areas of the world with little or no access to refined sugar show little or no caries. Because one of the major reservoirs of LB is fermented foods and dairy products, could it be that the modern diet also includes foods rich in LB, which, in addition to refined sugar, accounts for the severity of caries in 'modern' populations? It has been noted that Western diets differ from Eastern diets in that the latter is devoid of LB [Heilig et al., 2002]. We speculate that unlike $S$. mutans, which is a member of the normal indigenous biota, LB are opportunistic and exogenous bacteria and their sources lie outside humans in reservoirs as yet unidentified, but likely food from Western diets. Because LB are associated with advanced dentinal caries [Byun et al., 2004; Chhour et al., 2005], we wonder if LB contribute more than just acid to the fermentation of food products. A recent survey of LB associated with cheese processing showed that some strains of LB possess proteolytic properties [Sanchez et al., 2005] which, in theory, could accelerate the advancement of caries in the more connective tissue-rich dentin. It would be interesting to extend the studies of van Strijp et al. [1994] and survey strains of LB found in deep caries for proteolytic activity along with their genetic determinants.

\section{Acknowledgments}

This study was supported by research grant DE11147 and DE013937 from the National Institute of Dental and Craniofacial Research, National Institutes of Health, Bethesda, MD 20892. We thank Zheng-mei Lu and Zhen-zhen Zhuang for their technical assistance in the area of clinical microbiology. 


\section{References}

Antonio MA, Hillier SL: DNA fingerprinting of Lactobacillus crispatus strain CTV-05 by repetitive element sequence-based PCR analysis in a pilot study of vaginal colonization. J Clin Microbiol 2003;41:1881-1887.

- Becker MR, Paster BJ, Leys EJ, Moeschberger ML, Kenyon SG, Galvin JL, Boches SK, Dewhirst FE, Griffen AL: Molecular analysis of bacterial species associated with childhood caries. J Clin Microbiol 2002;40:1001-1009.

- Byun R, Nadkarni MA, Chhour KL, Martin FE, Jacques NA, Hunter N: Quantitative analysis of diverse Lactobacillus species present in advanced dental caries. J Clin Microbiol 2004;42:3128-3136.

-Carlsson J, Gothefors L: Transmission of Lactobacillus jensenii and Lactobacillus acidophilus from mother to child at time of delivery. J Clin Microbiol 1975;1:124-128.

Carlsson J, Grahnen H, Jonsson G: Lactobacilli and streptococci in the mouth of children. Caries Res 1975;9:333-339.

-Caufield PW, Cutter GR, Dasanayake AP: Initial acquisition of mutans streptococci by infants: evidence for a discrete window of infectivity. J Dent Res 1993;72:37-45.

-Caufield PW, Walker TM: Genetic diversity within Streptococcus mutans evident from chromosomal DNA restriction fragment polymorphisms. J Clin Microbiol 1989;27: 274-278.

Chhour KL, Nadkarni MA, Byun R, Martin FE, Jacques NA, Hunter N: Molecular analysis of microbial diversity in advanced caries. J Clin Microbiol 2005;43:843-849.

-Cole JR, Chai B, Farris RJ, Wang Q, Kulam SA, McGarrell DM, Garrity GM, Tiedje JM: The Ribosomal Database Project (RDP-II): sequences and tools for high-throughput rRNA analysis. Nucleic Acids Res 2005;33(database issue):D294-D296.

Cotter PD, Hill C: Surviving the acid test: responses of gram-positive bacteria to low $\mathrm{pH}$. Microbiol Mol Biol Rev 2003;67:429-453.

Hammes WP, Vogel RF: The Genus Lactobacillus. Glasgow, Chapman \& Hall, 1995.

-Heilig HG, Zoetendal EG, Vaughan EE, Marteau P, Akkermans AD, de Vos WM: Molecular diversity of Lactobacillus spp. and other lactic acid bacteria in the human intestine as determined by specific amplification of $16 \mathrm{~S}$ ribosomal DNA. Appl Environ Microbiol 2002;68:114-123.

Hillier SL, Krohn MA, Rabe LK, Klebanoff SJ, Eschenbach DA: The normal vaginal flora, $\mathrm{H}_{2} \mathrm{O}_{2}$-producing lactobacilli, and bacterial vaginosis in pregnant women. Clin Infect Dis 1993;16(suppl 4):S273-S281.
Hooper LV, Gordon JI: Commensal host-bacterial relationships in the gut. Science 2001; 292:1115-1118.

Hugenholtz P, Goebel BM, Pace NR: Impact of culture-independent studies on the emerging phylogenetic view of bacterial diversity. J Bacteriol 1998;180:4765-4774.

Keene HJ: Sampling of cariogenic microorganisms in human populations. Oral Microbiol Immunol 1986;1:7-14.

Kligler IJ, Gies WJ: A biochemical study and differentiation of oral bacteria with special reference to dental caries. J Allied Dental Soc 1915;10:445-458.

Li Y, Caufield PW: The fidelity of initial acquisition of mutans streptococci by infants from their mothers. J Dent Res 1995;74:681-685.

- Li Y, Caufield PW, Dasanayake AP, Wiener HW, Vermund SH: Mode of delivery and other maternal factors influence the acquisition of Streptococcus mutans in infants. J Dent Res 2005;84:806-811.

Loesche WJ, Eklund S, Earnest R, Burt B: Longitudinal investigation of bacteriology of human fissure decay: epidemiological studies in molars shortly after eruption. Infect Immun 1984;46:765-772.

London J: The ecology and taxonomic status of the lactobacilli. Annu Rev Microbiol 1976; 30:279-301.

Lu Z, Li Y, Lee W, PW C: Acquisition of L. acidophilus and L. casei in infants. J Dent Res 1999;78:257.

Marchant S, Brailsford SR, Twomey AC, Roberts GJ, Beighton D: The predominant microflora of nursing caries lesions. Caries Res 2001; 35:397-406.

Marmur J, Doty P: Determination for the base composition of deoxyribonucleic acid from its thermal denaturation temperature. J Mol Biol 1962;5:109-118.

Marsh P, Martin MV: The resident oral microflora; in Oral Microbiology. Woburn, Reed Educational and Professional Publishing Ltd, 1999, pp 7-33.

-Munson MA, Banerjee A, Watson TF, Wade WG: Molecular analysis of the microflora associated with dental caries. J Clin Microbiol 2004;42:3023-3029.

Pavlova SI, Kilic AO, Kilic SS, So JS, Nader-Macias ME, Simoes JA, Tao L: Genetic diversity of vaginal lactobacilli from women in different countries based on 16S rRNA gene sequences. J Appl Microbiol 2002;92:451-459.

Rogosa M, Mitchell JA, Wiseman RF: A selective medium for the isolation and enumeration of oral lactobacilli. J Dent Res 1951;30:682689.

Saitou N, Nei M: The neighbor-joining method: a new method for reconstructing phylogenetic trees. Mol Biol Evol 1987;4:406-425.
Sanchez I, Sesena S, Poveda JM, Cabezas L, Palop L: Phenotypic and genotypic characterization of lactobacilli isolated from Spanish goat cheeses. Int J Food Microbiol 2005;102: 355-362.

Satokari RM, Vaughan EE, Smidt H, Saarela M, Matto J, de Vos WM: Molecular approaches for the detection and identification of bifidobacteria and lactobacilli in the human gastrointestinal tract. Syst Appl Microbiol 2003; 26:572-584

Swofford D: Phylogenetic Analysis Using Parsimony, version 4.0 , beta 10 documentation. Sunderland, Sinauer, 1998.

Syed SA, Loesche WJ: Efficiency of various growth media in recovering oral bacterial flora from human dental plaque. Appl Microbiol 1973;26:459-465.

Tannock GW: A special fondness for lactobacilli. Appl Environ Microbiol 2004;70:31893194.

Tanzer JM, Livingston J, Thompson AM: The microbiology of primary dental caries in humans. J Dent Educ 2001;65:1028-1037.

Thompson JD, Higgins D, Gibson T: CLUSTAL W: improving the sensitivity of progressive multiple sequence alignment through sequence weighing, position-specific gap penalties and weight matrix choice. Nucleic Acids Res 1994;22:4673-4680.

van Houte J: Bacterial specificity in the etiology of dental caries. Int Dent J 1980;30:305326.

van Strijp AJ, van Steenbergen TJ, de Graaff J, ten Cate JM: Bacterial colonization and degradation of demineralized dentin matrix in situ. Caries Res 1994;28:21-27.

Walter J, Hertel C, Tannock GW, Lis CM, Munro K, Hammes WP: Detection of Lactobacillus, Pediococcus, Leuconostoc, and Weissella species in human feces by using group-specific PCR primers and denaturing gradient gel electrophoresis. Appl Environ Microbiol 2001;67:2578-2585.

Wicht MJ, Haak R, Schutt-Gerowitt H, Kneist S, Noack MJ: Suppression of caries-related microorganisms in dentine lesions after shortterm chlorhexidine or antibiotic treatment. Caries Res 2004;38:436-441.

Wright JT, Cutter GR, Dasanayake AP, Stiles HM, Caufield PW: Effect of conventional dental restorative treatment on bacteria in saliva. Community Dent Oral Epidemiol 1992;20:138-143.

Zhong W, Millsap K, Bialkowska-Hobrzanska H, Reid G: Differentiation of Lactobacillus species by molecular typing. Appl Environ Microbiol 1998;64:2418-2423. 